\title{
Changing patients' position in bed after non-emergency coronary angiography reduced back pain
}

Chair SY, Taylor-Piliae RE, Lam G, et al. Effect of positioning on back pain after coronary angiography. J Adv Nurs 2003;42:470-8.

In patients who have had non-emergency coronary angiography (CATH), does changing their position in bed reduce back pain without increasing the incidence of bleeding from the catheter insertion site?

\section{METHODS}

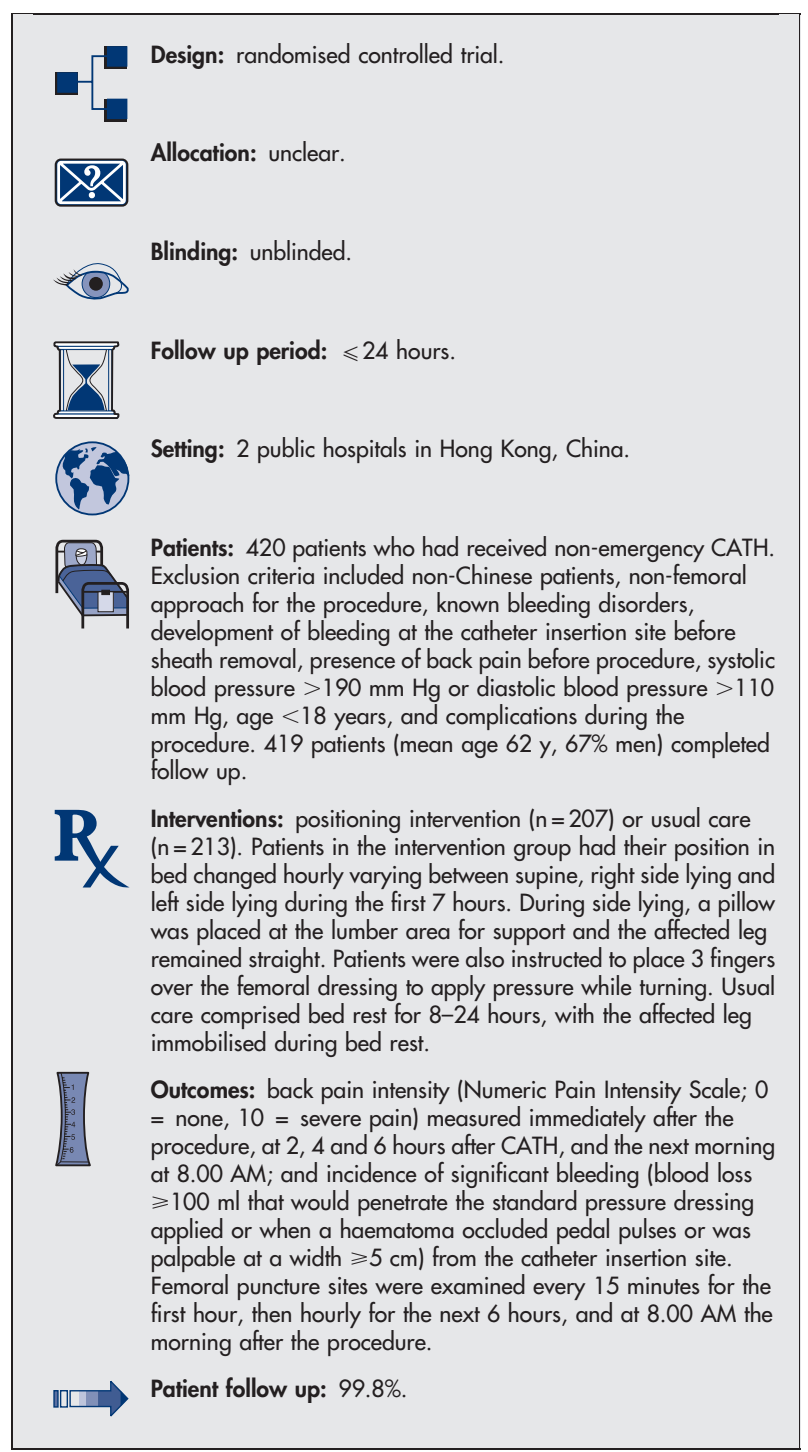

For corresponde Chinese University of Hong Kong, Shatin, New Territories, Hong Kong, China. sychair@cuhk.edu.hk

Source of funding: no external funding.

\section{MAIN RESULTS}

During the first 6 hours, increase in back pain intensity was lower in the intervention group than in the usual care group $(\mathrm{p}<0.001)$, with the intervention group reporting lower levels of back pain at all the 5 pain assessment times. The groups did not differ for incidence of significant bleeding ( $1 \vee 4$ patients, $\mathrm{p}=0.37$ ).

\section{CONCLUSION}

In patients who have had non-emergency coronary angiography, changing their position in bed reduced back pain without increasing the incidence of bleeding from the catheter insertion site.

\section{Commentary}

onventional care after CATH involving the femoral artery site routinely includes manual or mechanical site compression, keeping the affected extremity straight, and bed rest for 6-24 hours, to prevent bleeding from the insertion site. This care, guided largely by physician discretion or hospital standards, has not been based on empirical studies.

Back discomfort associated with restricted movement and prolonged immobilisation after CATH is a common patient complaint. ${ }^{1}$ The optimal length of time for bed rest is unknown, and until recently, little was known about the effect of positional change on outcomes. However, Chair et al have extended the findings of a previous study, ${ }^{2}$ which found that side lying was as safe as the supine position and more comfortable for patients. This result is also consistent with research that shows that elevating the head of the bed by $15-45^{\circ}$ after CATH reduced back pain and promoted wellbeing without an increase in vascular complications. ${ }^{1}$

The combined findings of studies on the effect of positional change will enable nurses to increase patient comfort safely. Altering a patient's position by $15-45^{\circ}$ head elevation and side to side positioning will enhance patient comfort, reduce back pain, and enable them to meet self care needs such as eating, drinking, and voiding. However, early ambulation may be the best strategy to offset back discomfort after CATH. Studies have shown that earlier ambulation (2-4 v 5-6 h after CATH) resulted in greater patient satisfaction with care and no difference in incidence of bleeding complications. ${ }^{3} 45$

Gerry Benson, RN, MSc School of Nursing, McMaster University Hamilton, Ontario, Canada

1 Coyne C, Baier W, Perra B, et al. Controlled trial of backrest elevation after coronary angiography. Am J Crit Care 1994;3:282-8.

2 Rein $A$, Zhu $Y$, Parkhurst $M$, ef al. Positioning post-outpatient cardiac catheterization. Prog Cardiovasc Nurs 1995;10:4-10.

3 Logemann T, Luetmer P, Kaliebe J, et al. Two versus six hours of bed rest following left-sided cardiac catheterization and a meta-analysis of early ambulation trials. Am J Cardiol 1999;84:486-8, A10.

4 Vlasic W, Almond D. Research-based practice: reducing bedrest following cardiac catheterization. Can J Cardiovasc Nurs 1999:10:19-22.

5 Mah J, Smith H, Jensen L. Evaluation of 3-hour ambulation post cardiac catheterization. Can J Cardiovasc Nurs 1999;10:23-30. 